\title{
A Comparative Evaluation of Smear Layer Removal Using Apical Negative Pressure (EndoVac), Sonic Irrigation (EndoActivator) and Er:YAG laser -An In Vitro SEM Study
}

\author{
Sanghamitra Suman ${ }^{1}$, Promila Verma ${ }^{2}$, Aseem Prakash-Tikku ${ }^{2}$, Rhythm Bains ${ }^{3}$, Vijay Kumar-Shakya ${ }^{4}$
}

${ }^{1}$ Post Graduate Student, Department of Conservative Dentistry \& Endodontics, Faculty of Dental Sciences, King George's Medical University, Lucknow, Uttar Pradesh, India

${ }^{2}$ Professor, Department of Conservative Dentistry \& Endodontics, Faculty of Dental Sciences, King George's Medical University, Lucknow, Uttar Pradesh, India

${ }^{3}$ Associate Professor, Department of Conservative Dentistry \& Endodontics, Faculty of Dental Sciences, King George’s Medical University, Lucknow, Uttar Pradesh, India

${ }^{4}$ Assistant Professor, Department of Conservative Dentistry \& Endodontics, Faculty of Dental Sciences, King George's Medical University, Lucknow, Uttar Pradesh, India

Correspondence:

Department of Conservative Dentistry \& Endodontics

Faculty of Dental Sciences

King George's Medical University

Lucknow, Uttar Pradesh, India

promilarajesh@yahoo.co.in

\begin{abstract}
Suman S, Verma P, Prakash-Tikku A, Bains R, Kumar-Shakya V. A Comparative Evaluation of Smear Layer Removal Using Apical Negative Pressure (EndoVac), Sonic Irrigation (EndoActivator) and Er:YAG laser -An In Vitro SEM Study. J Clin Exp Dent. 2017;9(8):e981-7.

\section{http:/www.medicinaoral.com/odo/volumenes/v9i8/jcedv9i8p981.pdf}

Received: 27/03/2017 Accepted: 02/07/2017

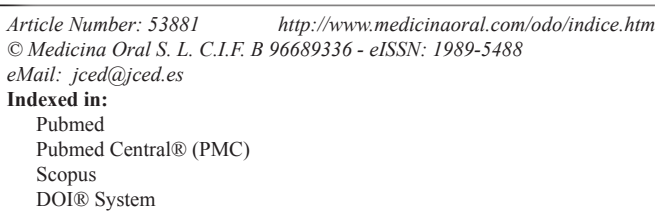

\begin{abstract}
Background: This study aimed to compare the smear layer removing efficacy of the EndoActivator, EndoVac and Er:YAG laser in extracted mandibular premolars, at the apical, middle and coronal third of root canal, through scanning electron microscopy.

Material and Methods: 40 extracted mandibular premolars were decoronated to a standardized length of $12 \mathrm{~mm}$. Specimens were shaped to ProTaper F4 size and irrigated with $5.25 \%$ sodium hypochlorite at $37^{\circ} \mathrm{C}$ between instrumentation. Teeth were divided into four groups $(\mathrm{n}=10)$, one control (needle irrigation) and three experimental, according to the irrigant activation technique used i.e. sonic irrigation (EndoActivator), apical negative pressure (EndoVac) or laser (Er:YAG). The final irrigants used were 10ml,17\% ethylenediaminetetraacetic acid (EDTA) and $10 \mathrm{ml}, 5.25 \%$ sodium hypochlorite. Root canals were then split longitudinally and observed under a scanning electron microscope. The presence of smear layer at the apical, middle and coronal third of root canal was evaluated. Scores were analyzed by Kruskal-Wallis and Mann-Whitney U tests. Intraexaminer and interexaminer reliability were determined by Kappa test.

Results: The EndoVac system was significantly more effective in removing debris from the apical third than all other groups. EndoActivator performed better than laser at the apical third. All three experimental groups (EndoVac, EndoActivator, and laser) were better than needle irrigation at the middle and apical third. At the coronal third, no significant difference was seen between the four groups.
\end{abstract}


Conclusions: None of the activation systems completely removes the smear layer from the dentine walls; nevertheless, EndoVac is significantly better in removing debris from the apical third of canal.

Key words: EndoVac, EndoActivator, Er:YAG laser, smear layer, scanning electron microscopy.

\section{Introduction}

One of the prerequisites of a successful endodontic treatment is an efficient removal of smear layer from the dentinal walls. A complete debridement of the root canal is essential to achieve an effective disinfection and a three-dimensional obturation for a favorable long-term prognosis (1-3).

Traditional needle irrigation has been proved to be insufficient for a complete cleaning of the complex anatomy of root canal system (especially the lateral canals, isthmuses and the apical third), therefore endeavors are being made to develop new irrigants and irrigating devices to improve the root canal disinfection in everyday endodontic practice (4-6). Apical negative pressure (EndoVac), sonic activation (EndoActivator) and Er: YAG laser are three such promising techniques that claim to improve the irrigant's effectiveness particularly at the apical third of canal. EndoActivator (EA) ((Dentsply, Tulsa Dental Specialties, Tulsa, OK), the sonically driven irrigant activation system, works on the principle of sonic activation of files $(1-6 \mathrm{kHz})$ to produce hydrodynamic intracanal fluid agitation (7-8). The EndoVac System (EV) (Discus Dental, Culver City, CA, USA) is an apical negative pressure irrigation device that is designed to drain irrigating solutions at the apical third of canal by overcoming the vapor lock effect (9). The laser helps in smear layer removal by its combined effect of photoablation and photoacoustic streaming (10). Er: YAG laser has been proven to be the most efficient among the available laser systems in smear layer removal and has also been approved by FDA to be used in endodontics (11-12).

This study was conducted for an in vitro comparative evaluation of the smear layer removing efficacy of these three systems (EA, EV, and Er:YAG laser) at the apical, middle and coronal third of root canal under the scanning electron microscope.

\section{Material and Methods}

Recently extracted human mature permanent mandibular premolars were collected from the Department of Oral and Maxillofacial Surgery, King George's Medical University, Lucknow. The teeth were digitally radiographed using both buccal and proximal views to confirm a single patent root canal devoid of any complex root canal anatomy. Teeth selected had root curvature not greater than 10 degrees and root length not shorter than $12 \mathrm{~mm}$. Teeth were then examined under a $\times 20$ magnification laboratory microscope (Stemi DV4 Spot; Carl
Zeiss, Oberkochen, Germany) for the absence of any caries, restorations or cracks. Calculus and other soft tissue debris were removed and teeth were autoclaved for 40 minutes to prevent and reduce any microbial growth during storage. The samples were stored in an aqueous solution containing $0.2 \%$ thymol to avoid dehydration. Teeth were decoronated, and root length was standardized to $12 \mathrm{~mm}$ by using a diamond disc operated at low speed.

-Sample preparation:

An ISO size \#10 K file (Dentsply Maillefer, Ballagues, Switzerland) was inserted into the root canal until just visible at the apical foramen. The working length (WL) was established $1 \mathrm{~mm}$ short of the length. Each apex was sealed with sticky wax to simulate the clinical situation. A coronal reservoir was created for irrigant placement with a size 4 Gates Glidden drill placed $4 \mathrm{~mm}$ into the canal (13). The root canals were prepared with ProTaper rotary instruments (Dentsply Maillefer, Ballaigues, Switzerland) up to apical size \#40 (F4). The canals were irrigated with $5 \mathrm{ml}, 5.25 \% \mathrm{NaOCl}$ between each file using a 30 gauge needle (NaviTip, Ultradent South Jordan, UT) placed $1 \mathrm{~mm}$ from the WL. The apical patency was checked after each instrument with a \#10 K-file. At the end of instrumentation, irrigation was done with $3 \mathrm{ml}$ saline to remove any remaining $\mathrm{NaOCl}$. The specimens were then randomly divided into four groups according to the activation modality of irrigants used $(n=10)$. In each group the final irrigants used were $10 \mathrm{ml}, 17 \%$ EDTA and $10 \mathrm{ml}, 5.25 \% \mathrm{NaOCl}$, activated according to the manufacturer's protocol.

-Final irrigation protocols:

GROUP-I: Control ( $\mathrm{n}=10)$

$10 \mathrm{ml}, 17 \%$ EDTA was delivered using a 30 gauge side vented needle (NaviTip) and left in place for 1 minute per canal. The procedure was then repeated with $10 \mathrm{ml}$, $5.25 \%$ sodium hypochlorite.

GROUP-II: EndoActivator /Sonic activation group: $(\mathrm{n}=10)$

Each canal was irrigated with $10 \mathrm{ml}, 17 \%$ EDTA using 30 gauge needle (NaviTip). The red (25/04) EndoActivator tip was used to activate intracanal solution at a speed of $10 \mathrm{kHz}$ for 1 minute (14). The procedure was repeated with $10 \mathrm{ml}, 5.25 \%$ sodium hypochlorite for 1 minute. The protocol used was as suggested by Ruddle (14).

GROUP-III: EndoVac/Apical negative pressure group: $(\mathrm{N}=10)$

30 seconds period of irrigation with $2.5 \mathrm{ml}, 5.25 \% \mathrm{NaO}-$ 
$\mathrm{Cl}$ was done by using the master delivery tip while the macrocannula was constantly moved up and down in the canal. This was followed by leaving the canal full of irrigant for 30s. Three irrigation cycles using the microcannula placed at full working length followed. The first cycle was $30 \mathrm{~s}$ of $2.5 \mathrm{ml}, 5.25 \% \mathrm{NaOCl}$ followed by 30 s of soaking; the second cycle was $1 \mathrm{~min}$ of $10 \mathrm{ml}, 17 \%$ EDTA followed by $1 \mathrm{~min}$ of soaking; and the third cycle was $1 \mathrm{~min}$ of $5 \mathrm{ml}, 5.25 \% \mathrm{NaOCl}$ followed by $1 \mathrm{~min}$ of soaking. The protocol is similar to that used by Parente (15).

GROUP-IV: Er:YAG laser: (N=10)

Er: YAG laser (2940 nm) with R-14 handpiece and 300$\mu \mathrm{m}$ endodontic fiber tip (AT Fidelis; Fotona, Ljubljana, Slovenia) was used at $50 \mathrm{~mJ}$ repetition rate of $10 \mathrm{~Hz}$ at $0.5 \mathrm{~W}$ (13) without air- water supply. $10 \mathrm{ml}$ of $17 \%$ EDTA was deposited with 30 gauge needle (NaviTip) into the canal. The laser tip was kept stationary at $5 \mathrm{~mm}$ from the working length and activated for three cycles of 15 seconds each with resting time of 5 seconds. The procedure was then repeated with $10 \mathrm{ml}, 5.25 \% \mathrm{NaOCl}$. The protocol is similar to that used by Ross (16).

Sample Preparation:

The roots were grooved longitudinally on the external surface with a diamond disc without penetration into the root canals and then split into two halves with a chisel. For each root, the half containing the most visible part of the endodontic wall was conserved (17). Selected half was divided into three sections by making grooves at 4 and $8 \mathrm{~mm}$ from the root apices by using a diamond bur. This was done to define the coronal, middle, and apical thirds. Each section was then secured on metal stubs, desiccated, sputter-coated with gold, and viewed with scanning electron microscopy.

-Scanning electronic microscope evaluation:

Smear layer removal was evaluated by the photomicrographs taken at 2,000 magnifications (Fig. 1). Four observers performed blind evaluation independently after examining the photomicrographs. The assessment was repeated by each observer after 15 days.

A 5-score index system codified by Hulsmann et al., (18) which measured the presence, quantity, and distribution of the smear layer was used to measure the smear layer removing efficiency. Score1 = no smear layer (dentinal tubules open), score $2=$ small amount of smear layer (some dentinal tubules open), score $3=$ homogenous smear layer covering the root canal wall (only a few dentinal tubules open), score $4=$ complete root canal wall covered by a homogenous smear layer (no open dentinal tubules), score 5 =heavy non-homogenous smear layer covering the complete root canal wall.

The Kappa test verified intraexaminer and interexaminer reliability for scanning electron microscopic assessment. The differences between irrigation techniques were compared non-parametrically using Kruskal-Wallis and Mann-Whitney $\mathrm{U}$ tests, $P$ values were computed and compared with statistical significance at the $P=0.05$ level. All statistical analyses were performed using IBM SPSS 20 software (IBM SPSS Inc., Chicago, IL).

\section{Results}

Kappa test results showed a strong intra and inter-examiner agreement at both Day 1 and 15 (Tables 1,2). The scores at coronal, middle and apical third for all four

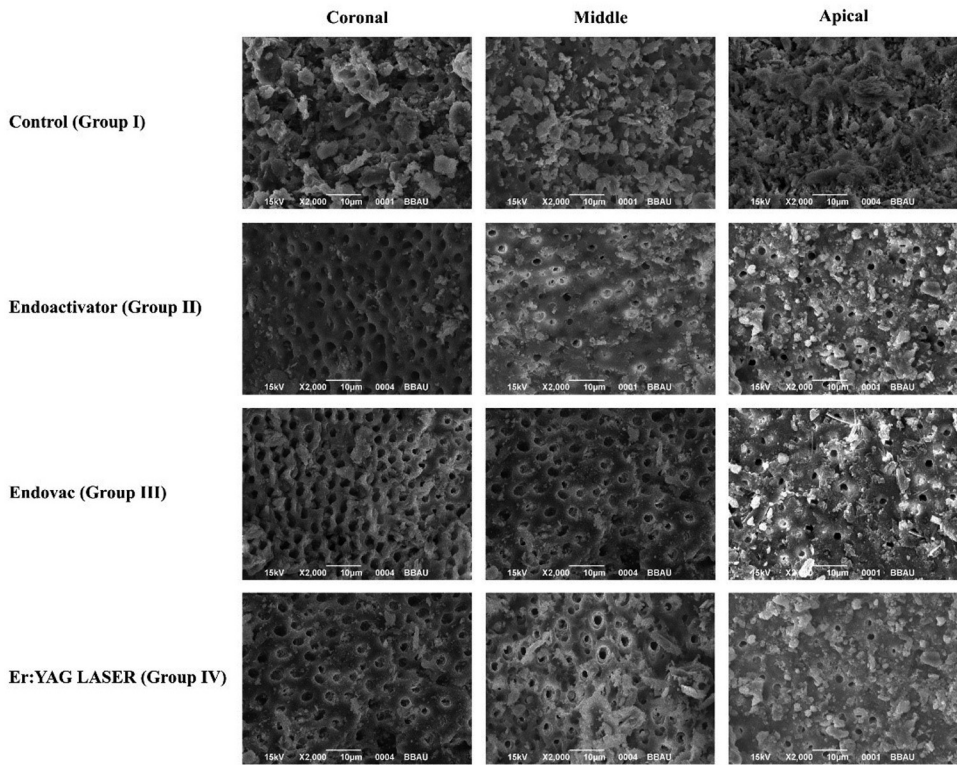

Fig. 1: SEM photomicrographs of the four groups at coronal, middle and apical third. 
groups was calculated as the mean score and standard deviation (Table 3, Fig. 2). At the apical third the mean score was highest for Control (5.0) followed by laser (4.47) and EA (4.01) and least for EV (3.49). The $P$ value was significantly different when Control was compared with $\mathrm{EV}(P=0.0001)$, EA $(P=0.01)$ and laser $(P=0.033)$. At the apical third, the cleaning efficacy of EV was better when compared to EA $(P=0.039)$ and laser $(\mathrm{P}=0.0001)$. EA proved to be better than laser in cleaning the smear layer at the apical third $(P=0.04)$. At the middle third mean score was highest for Control (4.31), followed by EA (3.63) and laser (3.72) and least for EV (3.40). There was a significant difference when Control was compared with EA $(P=0.0001), \mathrm{EV}(P=$ $0.0001)$ and laser $(P=0.00014)$. However, there was no significant difference seen between $\mathrm{EA}, \mathrm{EV}$, and laser $(P$
$>0.05)$. At the coronal third the mean score for Control (2.68) was highest, there was not much difference between the mean scores of EA (2.21), EV (2.03) and laser (2.22). However, there was no significant difference between the four groups $(P>0.05)$.

\section{Discussion}

The aim of this study was to evaluate the effect of three different irrigating systems (EndoVac, EndoActivator, and Er:YAG laser) in removing the smear layer at the apical, middle and coronal third of the dentinal wall. Past studies have compared these three systems individually with needle irrigation (19-21). Few studies have also compared EA with EV (22) or laser (23), but till now no study has attempted to compare the smear layer removing efficacy of EndoVac, EndoActivator, and Er:

Table 1: Comparison of inter-observer agreement at Day 1 and Day 15 at apical, middle and coronal third.

\begin{tabular}{|c|c|c|c|c|c|c|c|c|}
\hline & \multicolumn{2}{|c|}{ Observer 1 } & \multicolumn{2}{c|}{ Observer 2 } & \multicolumn{2}{c|}{ Observer 3 } & \multicolumn{2}{c|}{ Observer 4 } \\
\cline { 2 - 9 } & $\begin{array}{c}\text { Intra-class } \\
\text { correlation } \\
\text { coefficient } \\
\text { (ICC) }\end{array}$ & $\mathbf{9 5 \%}$ CI & $\begin{array}{c}\text { Intra-class } \\
\text { correlation } \\
\text { coefficient } \\
\text { (ICC) }\end{array}$ & $\mathbf{9 5 \%}$ CI & $\begin{array}{c}\text { Intra-class } \\
\text { correlation } \\
\text { coefficient } \\
\text { (ICC) }\end{array}$ & $\mathbf{9 5 \% ~ C I ~}$ & $\begin{array}{c}\text { Intra-class } \\
\text { correlation } \\
\text { coefficient } \\
\text { (ICC) }\end{array}$ & 95\% CI \\
\hline Apical & 0.92 & $0.85-0.95$ & 0.90 & $0.81-0.94$ & 0.91 & $0.85-0.95$ & 0.91 & $0.81-0.94$ \\
\hline Middle & 0.90 & $0.82-0.95$ & 0.91 & $0.84-0.95$ & 0.90 & $0.82-0.95$ & 0.90 & $0.84-0.95$ \\
\hline Coronal & 0.95 & $0.90-0.97$ & 0.97 & $0.95-0.98$ & 0.93 & $0.90-0.97$ & 0.97 & $0.95-0.98$ \\
\hline
\end{tabular}

Table 2: Comparison of intra-observer agreement from Day 1 to Day 15 at apical, middle and coronal third.

\begin{tabular}{|c|c|c|c|c|}
\hline & \multicolumn{2}{|c|}{ Day 1 } & \multicolumn{2}{c|}{ Day 15 } \\
\cline { 2 - 5 } & $\begin{array}{c}\text { Intra-class correlation coefficient } \\
\text { (ICC) }\end{array}$ & $\mathbf{9 5 \%}$ CI & Intra-class correlation coeffi- \\
cient (ICC) & 95\%CI \\
\hline Apical & 0.90 & $0.85-0.96$ & 0.81 & $0.71-0.92$ \\
\hline Middle & 0.92 & $0.82-0.95$ & 0.85 & $0.65-0.90$ \\
\hline Coronal & 0.95 & $0.90-0.97$ & 0.90 & $0.81-0.94$ \\
\hline
\end{tabular}

Table 3: Comparison of mean score among different groups at apical, middle and coronal Third.

\begin{tabular}{|l|c|c|c|}
\hline Groups & $\begin{array}{c}\text { Apical } \\
(\text { Mean } \pm \text { SD) }\end{array}$ & $\begin{array}{c}\text { Middle } \\
(\text { Mean } \pm \text { SD) }\end{array}$ & Coronal (Mean \pm SD) \\
\hline Control & $5.0 \pm 0.31$ & $4.31 \pm 0.48$ & $2.68 \pm 0.51$ \\
\hline Endoactivator & $4.01 \pm 0.48$ & $3.63 \pm 0.51$ & $2.21 \pm 0.63$ \\
\hline Endovac & $3.49 \pm 0.67$ & $3.40 \pm 0.48$ & $2.03 \pm 0.680$ \\
\hline Laser & $4.47 \pm 0.63$ & $3.72 \pm 0.47$ & $2.22 \pm 0.70$ \\
\hline
\end{tabular}


YAG laser (with a plain fiber tip) with a constant volume of irrigant.

Bias can occur while selecting the images by SEM operators and also while scoring the SEM images by examiners (18). In this study, Kappa values showed excellent intraexaminer and interexaminer concordance at two separate time periods.

Although an in vivo scenario is preferred, the advantages of an in vitro study are the ability to ensure uniformity and control of variables. In this study, the apex of teeth was sealed with wax to simulate in vivo conditions such as gas entrapment in the root canal and periodontal ligament (22). A well-shaped and fully tapered canal is necessary to act as an adequate reservoir of irrigant (24). Instrumentation to size \#40 is required for an efficient irrigation for both positive and negative pressure systems (25). Hence, Gates Glidden drill \#4 (Dentsply, USA) was used to create a coronal reservoir for the irrigant, and biomechanical preparation was completed with Protaper rotary files F4. Between each instrumentation, canals were irrigated with $5.25 \% \mathrm{NaOCl}$ because of its antimicrobial and tissue dissolving properties (26). For the final irrigation the recommended combination of $10 \mathrm{~mL}, 17 \%$ EDTA and $10 \mathrm{ml}, 5.25 \% \mathrm{NaOCl}$ was used (27-29).

In the present study, selected laser was Er:YAG laser. The mid-infrared erbium lasers are highly absorbed in water and hydroxyapatite in comparison to visible and near-infrared electromagnetic radiation and hence are more efficient for smear layer removal and disruption of intracanal biofilms (30-31).

Laser irradiation may result in a potentially hazardous effect in periodontal tissue (32). The selected Er:YAG laser has lower thermal effects and hence lower thermal damage to the surrounding dental tissues (33-35). Moreover, 5 seconds resting period between each activation recommended by Gutknechet et al. was used to lower the thermal effects (36).

At the apical third, the mean score was highest for Control (5.0). Previous studies have proved needle irrigation in a closed system to be ineffective in delivering adequate volume and pressure of irrigant at the apical third (37-38). With a conventional syringe irrigation, the irrigating solution is delivered only $1 \mathrm{~mm}$ deeper than the tip of the needle (39). This limits the penetration depth of the irrigating solution resulting in less effective smear removal from the apical third (40-41).

The apex of the samples in this study was sealed with glue and thus behaved as a closed-end channel. This might have resulted in gas entrapment at its closed end, producing the vapor lock effect (15). Except for EV, this phenomenon might have been present in all three groups (i.e. EA, laser and needle irrigation). In samples irrigated with EV, due to a continuous supply of fresh irrigant being delivered by negative pressure, vapor lock effect might have been avoided, resulting in better cleaning in the apical third (19).

At the apical third, the cleaning efficacy of EV was significantly better than needle irrigation. A similar result was described by Heilborn et al.; (42), Parente et al.; (15), S. Chris (19) who showed significantly better cleaning with EV compared with traditional positive-pressure irrigation. The apical negative pressure irrigation in EV results in a significantly more volume of irrigant delivered at apical third, without the risk of periapical extrusion (43-44).

EV performed significantly better than EA at apical third. These results are similar to showed by M. Manuele et al.; (22). EndoActivator works on the principle of hydrodynamic agitation of irrigant but acoustic microstreaming can only occur in a liquid phase. Therefore, once a sonic activated tip leaves the irrigant and enters the apical vapor lock, acoustic microstreaming, and cavitation becomes physically impossible (20). Since EA in spite of its hydrodynamic activation cannot overcome the vapor lock effect, it resulted in a less effective cleaning (22). Conversely in a recent study smear layer removing efficacy of EA was found to be better than EV (45).

EA performed better than Needle irrigation at apical third. These results are in contrast to past studies in which no significant difference was reported in smear layer removing efficacy of EV and needle irrigation (4647). This difference might be due to the lower volume of final irrigant used compared to the present study.

Er:YAG performed better than Needle irrigation at apical third. Similar results have been reported in the past by G. Rebecca (21) and de Groot (48). Laser results in an impulsive activation of irrigant at every pulse in contrast with steady streaming of irrigant with needle activation resulting in more efficient smear removal (21).

In this study, both EV and EA performed better than Er:YAG laser at apical third. This might be attributed to the hydrodynamic movement present with $\mathrm{EV}$ and EA resulting in vigorous intracanal fluid agitation (16). Whereas the effect with laser is mainly linear and the optical fiber may not have reached all the surfaces of the root canal walls (48). The difference might also be attributed to the placement of tip. While the tip of both EV and EA was placed at apex, the laser tip was kept stationary at $5 \mathrm{~mm}$ from the WL.

At the middle third, all the Groups performed better than Control. These results differ from those reported by Nielson and Baumgartner in which EV performed better than needle irrigation at $1 \mathrm{~mm}$ from $\mathrm{WL}$, but there was no difference seen at $3 \mathrm{~mm}$ (43). This may be attributed to not keeping the volume of irrigant constant in compared groups, (unlike the present study).

There was no significant difference seen between EA, $\mathrm{EV}$, and laser at the middle third. Similar results were reported by Manuele Mancini et al. in which no significant 
difference was seen in the cleaning efficacy of EV and EA at 3,5 and $8 \mathrm{~mm}$ from the apex (22).

At the coronal third, no significant difference was observed between the four groups. The process of smear layer removal was more efficient in the coronal and middle third than in the apical third of the canal, for all four groups. This is in agreement with previous studies (21, 42). The diameter of a root canal decreases on moving from coronal to apical third. Hence while irrigating, the coronal dentin is exposed to a higher volume of irrigants and allows for a better flow of the solutions as compared to apical dentin, resulting in better smear layer removal from coronal third (22).

Recently Er:YAG laser with a conical fiber tip (Photon induced photo acoustic streaming, PIPS) has been introduced that claims to be more effective than Er:YAG laser with a plain fiber tip (49). Conversely, few recent studies proved Er:YAG laser with plain fiber tip to be more efficient in smear removal than that with conical fiber tip $(23,50)$. It was speculated that in PIPS technique since the laser tip is placed at the coronal third, it results in a less effective irrigant activation at apical third of canal. Further studies comparing EA, EV, Er:YAG (PIPS, conical fiber tip) and Er: YAG (plain fiber tip) should be carried out.

\section{Conclusions}

This study concluded that use of EndoActivator, EndoVac, and Er: YAG laser increases the smear layer removing efficiency at apical and middle third. EndoVac was more efficient than other techniques at apical third. EndoActivator performed better than Er: YAG laser at apical third.

\section{References}

1. Mc Comb D, Smith DC.A preliminary scanning electron microscopic study of root canals after endodontic procedures. J Endod. $1975 ; 1: 238-42$

2. Gutmann JL. Clinical, radiographic, and histologic perspectives on success and failure in endodontics. Dent Clin North Am. 1992;36:37992.

3. Siqueira JF Jr. Etiology of root canal treatment failure: why welltreated teeth can fail. Int Endod J. 2001;34:1-10.

4. Ram Z. Effectiveness of root canal irrigation. Oral Surg Oral Med Oral Pathol. 1977; 44:306-12.

5. Villas-Boas MH, Bernardineli N, Cavenago BC, Marciano M, Carpio-Perochena A, de Moraes GI, et al. Micro-computed tomography study of the internal anatomy of mesial root canals of mandibular molars. J Endod. 2011;37:1682-6.

6. Mu-oz HR, Camacho Cuadra K. In vivo efficacy of three different endodontic irrigation systems for irrigant delivery to working length of mesial canals of mandibular molars. J Endod. 2012;38:445-8.

7. Ruddle CJ. Hydrodynamic disinfection: tsunami endodontics. Dent Today. 2007; 26:114-7.

8. de Gregorio C, Estevez R, Cisneros R, Heilborn C, Cohenca N. Effect of EDTA, sonic and ultrasonic activation on the penetration of sodium hypochlorite into simulated lateral canals: an in vitro study. J Endod. 2009;35:891-5.

9. Miller TA, Baumgartner JC. Comparison of the antimicrobial efficacy of irrigation using the endovac to endodontic needle delivery. $\mathrm{J}$ Endod. 2010;36:509-11.
10. Matsumoto H, Yoshimine Y, Akamine A. Visualization of irrigant flow and cavitation induced by Er: YAG laser within a root canal model. J Endod. 2011;37:839-43.

11. Takeda FH, Harashima T, Kimura Y, Matsumoto K. A comparative study of the removal of smear layer by three endodontic Irrigants and two types of laser. Int Endod J. 1999;32:32-39.

12. DiVito E, Lloyd A. ER: YAG laser for 3-dimensional debridement of canal systems: use of photon-induced photoacoustic streaming. Dent Today. 2012;31:122,124-7.

13. Pedulla E, Genovese C, Campagna E, Tempera G, Rapisarda E. Decontamination efficacy of photon-initiated photoacoustic streaming (PIPS) of irrigants using low-energy laser settings: an ex vivo study. Int Endod J. 2012;45:865-70.

14. Ruddle CJ. Hydrodynamic disinfection: tsunami endodontics. Dentistry Today. 2007;26:114-7.

15. J. M. Parente, R.J.Loushine, L.Susin, L.Gu, S.W. Looney, R.N.Weller, et al. Root canal debridement using manual dynamic irrigation or the EndoVac for final irrigation in a closed system and an open system. Int Endod J. 2010;43:1001-12.

16. Yost RA, Bergeron BE, Kirkpatrick TC, Roberts MD, Roberts HW, Himel VT, et al. Evaluation of Four Different Irrigating Systems for Apical Extrusion of Sodium Hypochlorite. J Endod. 2015;41:1530-4. 17. Matthew Brunson, Carlos Heilborn, D. James Johnson. Effect of Apical Preparation Size and Preparation Taper on Irrigant Volume Delivered by Using Negative Pressure Irrigation System. J Endod. 2010;36:721-4

18. Hulsmann M, Hahn W. Complications during root canal irrigation: literature review and case reports. Int Endod J. 2000;33:186-93.

19. Chris Siu J. Craig Baumgartner. Comparison of the Debridement Efficacy of the EndoVac Irrigation System and Conventional Needle Root Canal Irrigation In Vivo. J Endod. 2010;36:1782-85.

20. Uroz-Torres D, González-Rodríguez MP, Ferrer-Luque CM. Effectiveness of the EndoActivator System in Removing the Smear Layer after Root Canal Instrumentation. J Endod. 2010;35:308-11.

21. Guidotti R, Merigo E, C Fornaini, Rocca JP, Medioni E, Vescovi P. Er:YAG 2,940-nm laser fiber in endodontic treatment: a help in removing smear layer. Lasers Med Sci. 2014;29:69-75.

22. Mancini M, Cerroni L, Iorio L, Armellin E, Cianconi L. Smear Layer Removal and Canal Cleanliness Using Different Irrigation Systems (EndoActivator, EndoVac, and Passive Ultrasonic Irrigation): Field Emission Scanning Electron Microscopic Evaluation in an In Vitro Study. J Endod. 2013; 39:1456-60.

23. Arslan D, Guneser MB, Dincer AN, Kustarci A, Er K, Siso SH. Comparison of Smear Layer Removal Ability of QMix with Different Activation Techniques. J Endod. 2016;42:1279-85.

24. de Gregorio C, Arias A, Navarrete N, Del Rio V, Oltra E, Cohenca N.Effect of apical size and taper on volume of irrigant delivered at working length with apical negative pressure at different root curvatures. J Endod 2013;39:119-24.

25. Brunson M, Heilborn C, Johnson DJ, Cohenca N. Effect of apical preparation size and preparation taper on irrigant volume delivered by using negative pressure irrigation system. J Endod. 2010;36:721-4.

26. Perez-Heredia M, Ferrer-Luque CM, Gonzalez-Rodriguez MP. The effectiveness of different acid irrigating solutions in root canal cleaning after hand and rotary instrumentation. J Endod. 2006;32:993-7. 27. Baker NA, Eleazer PD, Averbach RE, Seltzer S. Scanning electron microscopic study of the efficacy of various irrigating solutions. J Endod. 1975;1:127-35.

28. Baumgartner JC, Cuenin PR. Efficacy of several concentrations of sodium hypochlorite for root canal irrigation. J Endod. 1992;18:60512.

29. Ciucchi B, Khettabi M, Holz J. The effectiveness of different endodontic irrigation procedures on the removal of the smear layer: a scanning electron microscopic study. Int Endod J. 1989;22:21-8.

30. Takeda FH, Harashima T, Kimura Y, Matsumoto K. A comparative study of the removal of smear layer by three endodontic irrigants and two types of laser. Int Endod J. 1999;32:32-39.

31. Armengol V, Jean A, Marion D. Temperature rise during Er: YAG and Nd: YAG laser ablation of dentin. J Endod. 2000;26:138-41. 
32. Matsuoka E, Jayawardena JA, Matsumoto K. Morphological study of the Er, Cr: YSGG laser for root canal preparation in mandibular incisors with curved root canals. Photomed Laser Surg. 2005;23:480-4. 33. Yamazaki R, Goya C, Yu DG, Kimura Y, Matsumoto K. Effects of erbium, chromium: YSGG laser irradiation on root canal walls: a scanning electron microscopic and thermographic study. J Endod. 2001;27:9-12.

34. Kimura Y, Yonaga K, Yokoyama K, Kinoshita JI, Ogata Y, Matsumoto K. Root surface temperature increase during Er: YAG laser irradiation of root canals. J Endod. 2002;28:76-8.

35. Macedo RG, Wesselink PR, Zaccheo F, Fanali D, Van Der Sluis LW. Reaction rate of $\mathrm{NaOCl}$ in contact with bovine dentine: effect of activation, exposure time, concentration and $\mathrm{Ph}$. I Endod J. 2010;43:1108-15.

36. Gutknecht N, Franzen R, Meister J, Vanweersch L, Mir M. Temperature evolution on human teeth root surface after diode laser assisted endodontic treatment. Lasers Med Sci. 2005;20:99-103.

37. Tay FR, Gu LS, Schoeffel GJ, Wimmer C, Susin L, Zhang K et al. Effect of vapor lock on root canal debridement by using a side vented needle for positive pressure irrigant delivery. J Endod. 2010;36:74550 .

38. Abarajithan M, Dham S, Velmurugan N, Albuquerque VD, Ballal S, Senthilkumar H. Comparison of EndoVac irrigation system with conventional irrigation for removal of intracanal smear layer: an in vitro study. Oral Surg Oral Med Oral Pathol. 2011;112:407-411.

39. Ram Z. The effectiveness of root canal irrigation. Oral Surg Oral Med Oral Pathol. 1977;44:306-12.

40. Salzgeber RM, Brilliant JD. An in vivo evaluation of the penetration of an irrigating solution in root canals. J Endod. 1977;3:394-8.

41. O'Connell MS, Morgan LA, Beeler WJ, Baumgartner JC. A comparative study of smear layer removal using different salts of EDTA. J Endod. 2000;26:739-43.

42. Heilborn C, Reynolds K, Johnson JD, Cohenca N. Cleaning efficacy of an apical negative pressure irrigation system at different exposure times. Quintessence Int. 2010;41:759-67.

43. Nielson BA, Craig Baumgartner J. Comparison of the EndoVac to needle irrigation of root canals. J Endod. 2007;33:611-5.

44. Desai P, Himel V. Comparative safety of various intracanal irrigation systems. J Endod. 2009;35:545-9.

45. Castagnola R, Lajolo C, Minciacchi I, Cretella G, Foti R, Marigo $\mathrm{L}$, et al. Efficacy of three different irrigation techniques in the removal of smear layer and organic debris from root canal wall:a scanning electron microscope study. G Ital Endod. 2014;28:79-86.

46. Klyn SL, Kirkpatrick TC, Rutledge RE. In Vitro Comparisons of Debris Removal of the EndoActivator System, the F File, Ultrasonic Irrigation, and $\mathrm{NaOCl}$ Irrigation Alone after Hand-rotary Instrumentation in Human Mandibular Molars. J Endod. 2010;36:1367-71.

47. Uroz Torres D, Gonzalez M P, Ferrer CM. Effectiveness of the endo activator system in removing the smear layer after root canal instrumentation. J Endod. 2010;36:308-11.

48. de Groot SD, Verhaagen B, Versluis M, Wu MK, Wesselink PR, van der Sluis. LW. Laser-activated irrigation within root canals: cleaning efficacy and flow visualization. Int Endod J. 2009;42:1077-83. 49. George R, Meyers IA, Walsh LJ. Laser activation of endodontic irrigants with improved conical laser fiber tips for removing smear layer in the apical third of the root canal. J Endod. 2008;34:1524-7.

50. Deleu, E, Meire MA, De Moor RJ.Efficacy of laser-based irrigant activation methods in removing debris from simulated root canal irregularities. Lasers Med Sci. 2015;30:831-5.

\section{Conflict of Interest}

The authors deny any conflicts of interest. 